Elmar Kulke, Berlin

\title{
The technology park Berlin-Adlershof as an example of spatial proximity in regional economic policy
}

\begin{abstract}
Since the 1990s spatial economic policy increasingly tries to encourage the development of innovative firms especially in selected locations like technology parks. Spatial proximity in these locations should lead to the development of competitive clusters. The technology park Berlin-Adlershof is one example for this new approach of spatial economic policy; today it is according to the number of employees - one of the largest technology parks in Europe. This paper discusses to what extent spatial economic policy has contributed to the development of an interlinked cluster. First elements of spatial economic policy will be evaluated according to the network and cluster approaches. Then general considerations of cluster development will be confronted with the development path of Berlin-Adlershof. Finally the extent of network formation will be discussed. The economic dynamic in Berlin-Adlershof shows that a proximity-oriented approach of spatial economic policy has been successful. Spatial proximity has encouraged the development of networks between the units, but up to now networks between science and business are not very strong. Keywords: technology park, spatial proximity, spatial economic policy, Berlin-Adlershof, network development
\end{abstract}

\section{Introduction}

Since the mid-nineties structural and spatial economic policy in Germany has been increasingly influenced by the idea of developing sectoral or regional concentrations of interlinked production units (cf. ARL 2006; FLOETING 2008; FROMHOLD-EISEBITH/EISEBITH 2005; Mossig/Klein 2003; Rehreld 1999). On the regional level spatial economic policy often tries to encourage the development of sectoral clusters following a commodity chain; it is expected that companies belonging to one focal activity of economy and having intensive linkages with each other are gaining competitive advantages. On the local level technology centers and technology parks are an important policy instrument to encourage economic growth based on the spatial proximity of innovative firms (cf. BEHRENDT 1996; GUNDeL/LutTMAnN 2008; TAMAsy 1996). The guiding idea is that spatial proximity facilitates the development of linkages and communication between the units; this opens up the possibility not only of reducing transport and transaction costs but also of exchanging tacit knowledge, which generates joint learning processes and innovations. The innovative strength can be supported by institutions that provide special qualifications (e.g. universities, technical schools) and by the use of joint infrastructure facilities.

The technology park Berlin-Adlershof is one example of this new approach to spatial economic policy. Some fifteen years ago the first decisions were made for the development of a science and business park in Adlershof. The idea was to connect innovative new enterprises with research institutes and with university research and education; implicit in the concept was following the idea of generating - based on the spatial proximity of the units - an innovative and interlinked cluster. But more than that, the concept was following an agglomeration-oriented approach; there was the hope that simply by concentrating units at one location, networks would develop. Explicit instruments for network management were not used. Today reports of Adlershof's success are multiplying, and one sometimes encounters almost euphoric statements about the dynamics of the site. In his introduction to the 2005 annual report (WISTA 2006), Hardy R. Schmitz, head of 
WISTA Management GmbH, writes, "Earning money with science - Adlershof continues to grow: $12.5 \%$ more revenue, $10.8 \%$ more employment, $92 \%$ utilized rentable space, and only three insolvencies out of 400 companies. This is Berlin Adlershof's impressive balance sheet for the year 2005." And the German journal Der Spiegel heads its 2008 report on Adlershof: "Almost like China - in BerlinAdlershof a science and technology park is booming; for experts it is a typical example for the efficient use of subventions in the east".

These statements refer to the (possible) success of a "real-life experiment" that is interesting both for the scientific discussion in economic geography and for regional economic policy. During the last few decades - strongly influenced by Porter's discussion of the competitive advantages of clusters (PORTER 1993, 1999) - analysis of spatial concentrations of specialized economic activities has been a major field of research in economic geography (cf. AsheIm/COOKE/MarTin 2006). It is already widely accepted that these concentrations possess competitive advantages if the economic units are linked with each other by immaterial flows of knowledge and information. But it remains disputed as to whether, by means of spatial economic policy with initial government investments, networks, interlinkages and exchange of tacit knowledge in the sense of an innovative milieu or cluster of scientific and business activities can be created successfully (cf. CoOKE 2002, 157: "Can clusters be built?"), or if such economically competitive concentrations of interlinked activities - in the sense of geographical industrialization - only develop by themselves.

The paper starts with some general considerations concerning competitive clusters and on the economic policy of Berlin. It will be discussed to what extent policy really follows a cluster-oriented approach. Then the development path and present characteristics of the Adlershof science and technology park will be presented. Finally, based on empirical studies, it will be asked to what extent Adlershof exhibits elements and features of a competitive cluster.

\section{Advantages of spatial proximity}

The advantages of spatial proximity in business activities have long been discussed and are included in most model approaches in economic geography. The classic approaches discuss the advantages of agglomerations by concentrating on their cost-minimizing effects (cf. GORDON/MCCANN 2000, 516 f.; KulKE 2008, $125 \mathrm{f}$.). The proximity of delivery and processing services, providers of other services, consumers, and political decision makers reduces not only the transportation costs for material goods, but also the transaction costs of organizing and conducting business in networks and relationships. The successful extension of transportation and communication infrastructures over the last few decades has, however, led to a drastic decrease in transportation costs; they are accordingly less important today as elements of spatial differentiation.

At the same time, knowledge as a factor in production is gaining importance in highly developed societies (e.g. GERTLER 2001; KLINE/Rosenberg 1986). During the nineties there was a shift in spatial economic research, and since then technology, innovations, knowledge and creativity are seen as decisive factors in the spatial economic development of advanced economies (SCHAMP 2007). These observations in scientific research have influenced economic and spatial policy and find their expression in innovation-oriented approaches (cf. FROMHOLD-EISEBITH 1999; FrOMHOLD-EISEBITH/EISEBITH 2005).

The generation of innovations can be benefited by the spatial proximity of actors in research, development, and business. The innovative and competitive abilities belonging to spatial concentrations of economic activity are especially advantageous when the actors managing them possess strong personal and organizational linkages - usually referred to as networks (cf. BATHELT 1998; FROMHOLDEISEBITH 2000; KULKE 2008, 84 f.). The actors, meaning those who create, sustain and use the networks, come from complementary businesses, from research and educational facilities, and from various institutions. Functional relationships between these actors are based on reciprocity, trust, dialog, flexibility, and self-regulation. The networks within a spatial entity display a high degree of openness and intensity, in contrast to a certain amount of restraint with outside actors. For the successful long-term competitiveness of a network, however, not only strong internal link- 
ages, "strong ties", are essential but also the co-existence of outside (worldwide) linkages. Without these "weak ties," the lock-in-phenomenon can occur - that is, without a view of the outside world, new trends or innovations that have been successful elsewhere are not sufficiently perceived and, where applicable, integrated (cf. BATHELT/DEPNER 2003). These networks are useful (cf. GROTZ 1996) not only because of their classic economical advantages (e.g. the realization of economies of scale and economies of scope, advantages in terms of transaction costs, risk minimization), but above all because they allow the possibility of common processes of learning and innovation (learning by interaction). This is aided by the fact that within a network not only formal knowledge is exchanged, but also knowledge that has not yet been codified and made public, which is in part based on experience (tacit knowledge). This can usually, however, only take place through personal contact, making spatial proximity therefore very meaningful, and is scarcely replaceable by telecommunications. In addition spatial proximity opens up the possibility of observing the innovations of competitors, thereby increasing the innovative dynamics of enterprises, sustaining their position in competition. Inclusion in a common economic, cultural, social, and political environment (embeddedness) is also an important facet of the functionality of a network. Infrastructural facilities contribute to this, as do training stations or economically connected institutions.

The discussion shows that spatial proximity can encourage the development of networks and may contribute to the generation of innovations. These concentrations optimally form a functional cluster. According to PORTER (1998) a cluster is defined as follows: "A cluster is a geographical proximate group of interconnected companies and associated institutions in a particular field, linked by commonalities and complementarities." FESER (1998, 26) additionally points out the competitive advantage of these concentrations: "Economic clusters are not just related and supporting industries and institutions, but rather related and supporting institutions that are more competitive by virtue of their relationship."

Over time, a relatively large number of individual conceptual approaches to the spatial concentration of industry and innovative ac- tivities have arisen (cf. DANNENBERG 2007, 18 f.; KULKE 2008, 127 f.). Two of these clusteroriented concepts, the innovative milieu approach and the geographical industrialization approach, are concerned with the spatial concentration of innovative activities and they describe the development path of these clusters. They are suitable as explanatory substructures for the development in science and technology parks such as Berlin-Adlershof. Although these two approaches incorporate similar characteristics and elements, they differ decisively on the issue of the starting point and pathway of development. While the innovative milieu approach assumes that the existence of a milieu is a prerequisite for development, the geographical industrialization approach asserts that growth industries generate their own innovative surroundings. This difference in terms of the developmental starting point is critical for regional economic policy.

According to the milieu approach, policy should aim at bringing together research components, such as universities or research institutes, and support the resulting spin-off businesses; this is essentially the approach that has been taken at Berlin Adlershof. The innovative milieu approach is based primarily on the work of the French Groupe de recherché europeen sur les milieux innovateur (GREMI) (cf. Aydalot 1986). Aside from the basic idea that creativity arises from the mutual, frequent, and intense exchange of information, bringing together formerly unconnected knowledge and new solutions, the approach stresses the importance of the surrounding environment. This environment is in part created by the actors themselves, who, because of their common technical culture, social characteristics, and interests, produce a feeling of community and a site image. The milieu can also be cultivated by the adoption of suitable economic policy instruments and the setup of institutions suitable for a business environment. This includes support in the form of regional and scientific policy, as well as the generation of human capital by means of training and the development of institutions closely tied to business interests. Using this milieu as a basis, competitive economic activities in a specialized field of activity can then develop.

In contrast, according to the geographical industrialization approach, the settlement of key industries would be the deciding factor, 
the development of which could, if necessary, be supported by complementary facilities. First, many possible alternative sites exist for the locational choice of innovative new industries (window of locational opportunity; STORPER/WALKER 1989; cf. BATHELT 1992). Sites with a minimal density just outside of already existing agglomerations (which contain older production areas) are especially suitable. At the beginning of the development path, new production areas at multiple sites arise, yet as the expansion process progresses, only one of these survives (selective clustering). At this site, through the immigration of mobile production factors, it comes to an increased concentration of activity. The further settlement of businesses, start-ups, and spin-offs takes place, both of production industries and of the accompanying service industries. Additionally, a special surrounding environment of institutions and facilities develops, tailored to meet the needs of new activities of the area. In this case spatial economic policy only has to encourage the development of key industries and later to assist with the establishment of institutions.

After considering the model approaches, the question arises as to whether strengthening of linkages and networks between actors in different areas, dependent on the factor of spatial proximity, has taken place during the development path of the Adlershof site. It is also interesting to evaluate whether the observed growth dynamic is based primarily on the individual expansion of single enterprises and industrial segments (in the sense of geographical industrialization), or rather constitutes the result of networked activities and policy-led development of institutions (in the sense of the innovative milieu).

\section{Spatial economic policy in Berlin}

Spatial economic policy in Berlin has long assisted in the development of new firms and encouraged spin-offs from universities and research institutes. In the year 1983 the first business incubation center (BIG) of Germany was established in an old manufacturing building in West Berlin (RAETz/SEIFF 2003). Due to the positive experience, BIG has become the model for several further founder and innovation centers (TAMASY 1996). Especially after the reunification this instrument was extensively used to overcome the economic crisis in
Berlin (KULKE 2003). With reunification the manufacturing sector of Berlin faced severe problems. Many of the formerly subsidized manufacturing enterprises of former WestBerlin moved to other locations. In former East-Berlin almost $80 \%$ of the jobs in the manufacturing industries were lost, as production was not competitive in either national or international markets, and the enterprises had to close. The transformation process led to a major change in the employment structure of Berlin; today various services are the most important industries, while manufacturing activities only contribute less than $20 \%$ to the labor force. Berlin still has weaknesses in the size structure and technology intensity of manufacturing. Most notably, larger units with innovative products and a high share of research and development activities are missing. The manufacturing sector is dominated by smaller units that serve the local market (KuLKE 2003).

Berlin spatial economic policy faced the problem that resettlements of larger enterprises from other locations to Berlin were more or less an unrealistic idea. Therefore, the government concentrated its policy instruments on encouraging the development of small, new, technology-oriented enterprises, often established as spin-offs from universities. With the Business Plan Competition the policy is assisting new enterprises during the establishment phase by offering coaching services and organizing contacts to venture capital institutions. And the government is offering locations in founder/innovation centers and technology parks. In total, more than 900 Mio. $€$ (with 670 Mio. $€$ in public funding) were invested to build up these locations in Berlin (Fig. 1). Today there are six general business incubation centers and eleven innovation centers as well as five technology parks located in Berlin. They are offering more than $400,000 \mathrm{~m}^{2}$ of space to enterprises; approximately 1,100 enterprises with more than 13,000 employees are located there. Estimations including companies that have successfully moved out of the centers predict that more than 21,000 new jobs have been created through these initiatives (RAETZ/SEIFF 2003). The most important project is located in Berlin's Adlershof district; and this technology park today is not only the largest policy project in Berlin but, in terms of employment, the largest technology park in Germany. 
With the development of Adlershof in the 1990 s, a change in the concept of spatial economic policy in Berlin can be observed; the idea of spatial proximity of complementary units (influenced by Porter's idea of 1993 of competitive advantages) was increasingly influencing the strategy. Existing innovation-oriented approaches were completed by bringing together research, institutions, and enterprises at a single location. In contrast to the network and cluster models discussed earlier, the Berlin spatial economic policy since the 1990 s can be addressed as a heterogeneous proximity-oriented approach; there is a tendency toward innovative and technology-oriented firms, which is in some way influenced by the idea of cluster and network formation. In this sense it can be viewed as a top-down approach (FROMHOLDEISEBITH/EISEBITH 2005), but a direct influence on network formation is missing. Instead the concept is following the idea of spatial proximity of somewhat complementary units, which could, hopefully, lead to the development of networks and competitive advantages.

\section{Case study Berlin-Adlershof}

The main idea behind the development of the
Adlershof area was, at the beginning of the1990s, that three complementary elements - research and training at the university, research in institutes, and private business activities - would serve as the cornerstones of a resulting dynamic, growing, technology-oriented cluster (Fig. 2). In accordance with the GREMI innovative milieu approach, the starting point in Adlershof was the governmentsupported settlement of research institutions, supplemented by the support of newly founded enterprises. The concept was mainly stressing the spatial proximity factor, and, although not in an exact sense, the cluster idea. It was hoped that being at one location would be the basis for the development of networks and for a dynamic growth process.

\section{Historical background and long-term \\ development path}

The Adlershof site can look back on an almost hundred-year long history of being orientated toward modern technologies. This leads to the question as to whether a long-term development path can be observed. The development of networks, clusters, and milieus is often explained by the existence of a constant development path. The geographical industrialization model (STORPER/WALKER 1989) describes

Fig. 1: Location of founder/innovation centers and technology parks in Berlin

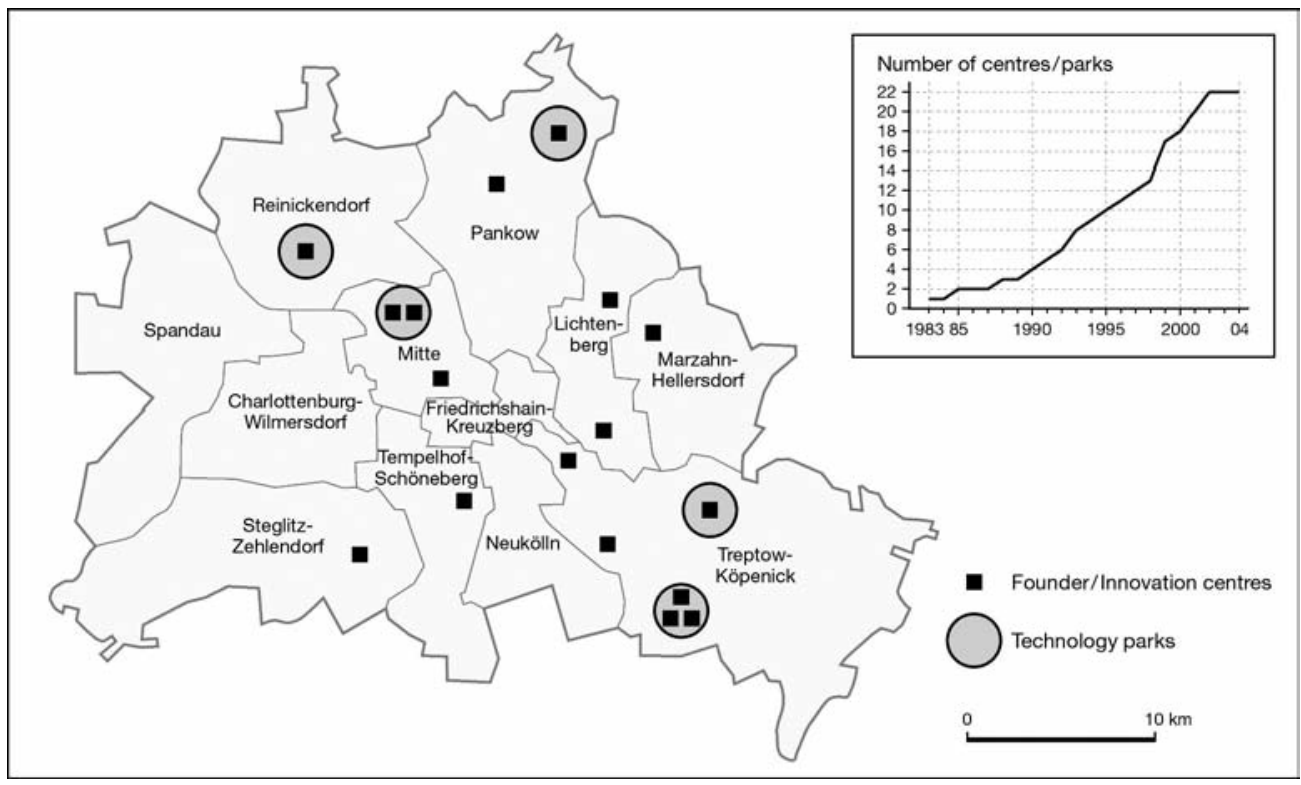

Source: RAETZ/SEIFF 2003 
the evolution of clusters. Later studies point out the importance of the development of trust, of routines in the organizational structure, of trial-and-error learning processes, or of spin-off processes (e.g. BELUSSI 2006; Boschma/FrenKen 2005; Mossig 2006; see also the case studies in COOKE/PICCALUGA 2006). Looking at the situation in Adlershof there seems to be a constant factor in the orientation toward modern technologies, but there have been several upheavals as a result of changes in the economic framework.

Fig. 2: Berlin-Adlershof zoning plan (2008)

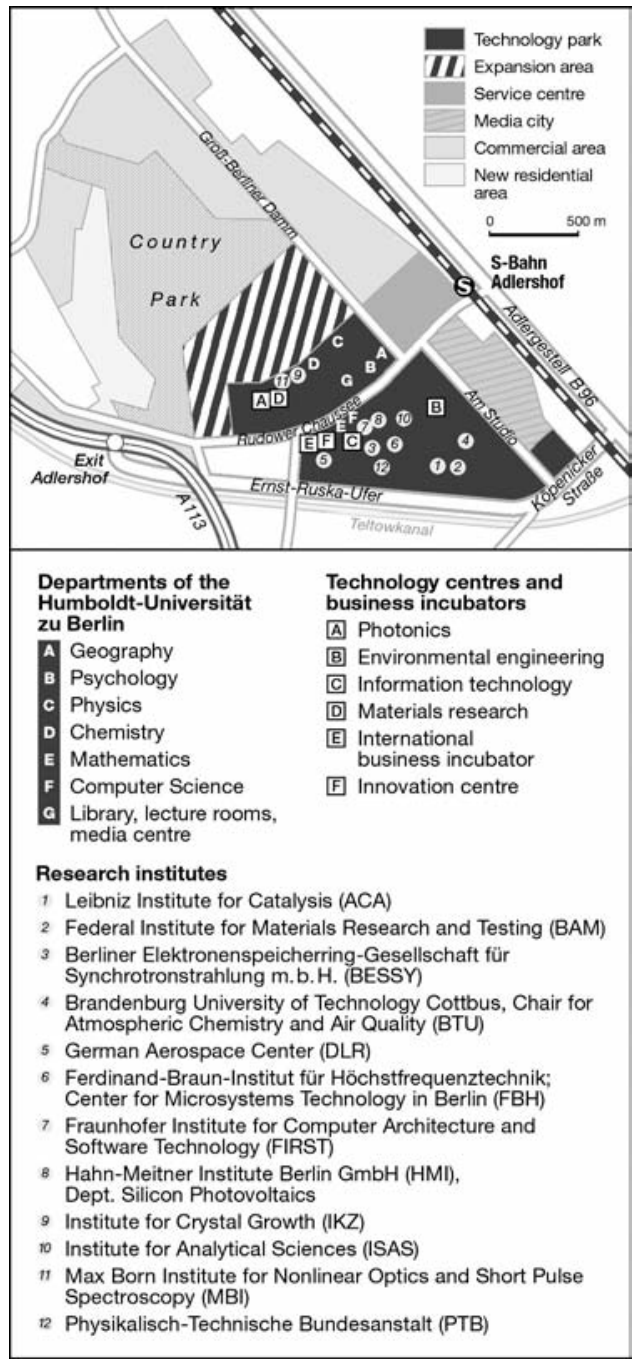

Before World War II the Adlershof area was clearly oriented toward aeronautical research and production. The first airport for enginepowered flights in Germany was opened here in 1909. Thereafter the associated research facilities and numerous production companies settled in the area. The founding of the Deutsche Versuchsanstalt für Luftfahrt DVL (German Laboratory for Aviation) followed in 1912. The DVL pursued scientifically based aviation research in wind tunnels, testing facilities, and factories, with over 500 employees in 1928 (WISTA 2006b). Alongside arose production companies for airplanes and their component parts. The Erich Rumpler Aircraft Construction Company (Flugzeugbau) and the Fokker Airplane Factory (Flugzeugwerke), for example, attained large market significance as producers of civilian and military aircraft, alongside many smaller operations (the so-called airplane builders, „Aeroplanbauer”).

These activities came to an end after World War II, and an extensive change in the scientific and economic orientation of the site took place. Aircraft production was no longer possible and most production-oriented activities ended. In research a strong shift towards natural sciences prevailed. The German Democratic Republic (GDR) housed the facilities of its German Academy of Sciences in the former DVL buildings from the early 1950s onward. By 1989, fifteen natural science institutes, primarily in the areas of physics and chemistry, had arisen in the area. Approximately 5,400 persons were employed in these institutes at the time of the German reunification in 1989 (HU 2005). Also on the premises was the $\mathrm{Se}$ curity Regiment Felix Dzerzhinsky of the $\mathrm{Na}$ tional People's Army (Nationale Volksarmee), as well as studios, production offices, and broadcasting facilities belonging to GDR television broadcasting institutions.

With the reunification came renewed upheaval in Adlershof. The military facilities were immediately closed, the television broadcasting facilities dissolved and privatized. The breakup of the erstwhile German Academy of Sciences facilities took a more differentiated path. Its sections that had been strongly oriented toward industrial development were for the most part closed, some of them re-emerging as an assortment of newly founded, private-sector enterprises. Those that had focused on basic research became the basis for 
the construction of state-financed research institutes belonging to the Max Planck, Fraunhofer, or Leibniz scientific societies. The founding of new, technologically oriented private enterprises (particularly in technology parks) was supported by the state. And, in 1991, the official decision was made to relocate Humboldt University's natural sciences institutes from the central district of BerlinMitte to Berlin-Adlershof.

Looking at the history of the location, no longterm development path in the sense of an evolution of specific areas of innovation and production can be observed (cf. Boschma/ FRENKEN 2005). Instead there have been several upheavals with an accompanying total change in technological orientation. The technological orientation and the production structure before WWII and the research orientation in the GDR period were completely different. And with the German reunification a profound change occurred once again. Production and private enterprises became a new element at the location, several units of the academy of sciences were closed and new research units with a different orientation were established. The only seedbed for constant relations were the still-existing personal ties between the groups of persons who before had worked in the academy of sciences and who afterwards either established private enterprises or were employed in new research institutes. These linkages still exist to a certain extent and find their expression in the occasional use of some material infrastructure or in the private exchange of information. But they are relatively limited, so with the establishment of the technology park after the reunification a new start was made; a developmental continuity can therefore be examined only from the 1990s onward.

\section{Development since German reunification and current structures}

From the very beginning of the development of the technology park, spatial economic policy followed the idea of establishing three complementary cornerstones: enterprises, research institutes, and university institutes. They were settled in the area step by step. The process began immediately after German reunification with the establishment and support of start-up companies - some of them spinoffs of the former German Academy of Sciences - and with the reorganization of the research institutes. The resettlement of university institutes of Humboldt University needed several years, the first unit being established not until 1998 in Adlershof. For the organization of the park's development of the park the Berlin government established a public-private company called WISTA. WISTA is the operating company for the park; it was responsible for the construction, lease and operation of the technology and incubator centers. Today it offers rental space and maintains properties for sale; it promotes research and

Tab. 1: Business and employment in Berlin-Adlershof (2006)

\begin{tabular}{|c|c|c|c|}
\hline & $\begin{array}{l}\text { Number of } \\
\text { units } \\
\text { (end 2006) }\end{array}$ & $\begin{array}{l}\text { Number of } \\
\text { employees } \\
\text { (end 2006) }\end{array}$ & $\begin{array}{l}\text { Turnover/budget } \\
\text { (Mio. } € \text { in 2006) }\end{array}$ \\
\hline \multicolumn{4}{|l|}{ Technology park } \\
\hline Businesses & 400 & 4,279 & 440 \\
\hline Research institutes & 12 & 1,508 & 142 \\
\hline University institutes & 6 & $\begin{array}{l}865 \\
\text { (plus } 6.434 \text { students) }\end{array}$ & 55 \\
\hline Sub-total & 418 & $\begin{array}{l}6,652 \\
\text { (plus } 6,434 \text { students) }\end{array}$ & 637 \\
\hline \multicolumn{4}{|c|}{ Media City and industrial/service park } \\
\hline Businesses & 138 & 1,432 & 188 \\
\hline Businesses & 201 & 4,261 & 491 \\
\hline Total & 757 & $\begin{array}{l}12,345 \\
\text { (plus } 6,434 \text { students) }\end{array}$ & 1316 \\
\hline
\end{tabular}


business networks as well as national and international joint ventures. And it is responsible for public relations, marketing, and sales activities for the entire development area (cf. WISTA 2007). Today there are more than 750 enterprises with more than 12,000 employees working in Adlershof, and more than 6,400 students are educated there (Tab. 1).

\section{Private enterprises and business centers}

The policy for private enterprises was guided mainly by the idea of facilitating their development by offering well-equipped spaces at low rents. On the Adlershof site locations for private enterprises were available on free spaces, in some existing old buildings - especially in the so-called industrial park outside the core area of the technology park (Tab. 1) and in newly established business centers. The industrial park was mainly designated for classical manufacturing and service activities, while the technology park was designed to host innovative firms and research units (Fig. 2 ). Today space is available the technology park in two incubation centers, four technology centers and in several sites for lease.

The first step for the foundation of new technologically oriented enterprises was the estab- lishment of the Innovation and Business Incubation Center Berlin (Innovations- und Gründer-Zentrum Berlin-Adlershof, IGZ), in Adlershof in September 1991. The center began in a plain, one-story building with an area of around $1,000 \mathrm{~m}^{2}$, on which five companies and their fourteen employees settled (data, aöso in the following, based on RAETZ 2005). Later a new building with an area of $11,800 \mathrm{~m}^{2}$ was erected and then extended in 1997 with the Ost-West-Zentrum (OWZ), comprising an additional $6,600 \mathrm{~m}^{2}$. The OWZ focuses primarily on international businesses. Both the IGZ and OWZ offer the infrastructures typical for the Technology and Start-Up Center (TGZ), e.g. secretary services, conference rooms (cf. TAMASY 1996), and render manifold human capital-intensive services (counsel in all business matters; contact to distributors, financial institutions, buyers, and service providers; team-building) in order to minimize the initial difficulties of younger businesses. In the period from 1991 to July 2005, 297 businesses moved there, and only fifteen insolvencies occurred (Fig. 3), which can be assessed as a success. According to the TGZ conception, businesses are to stay in these centers for only a limited amount of time (i.e. during their initial phases) and then, with further growth, to

Fig. 3: Performance of IGZ/OWZ*1991 - 2005

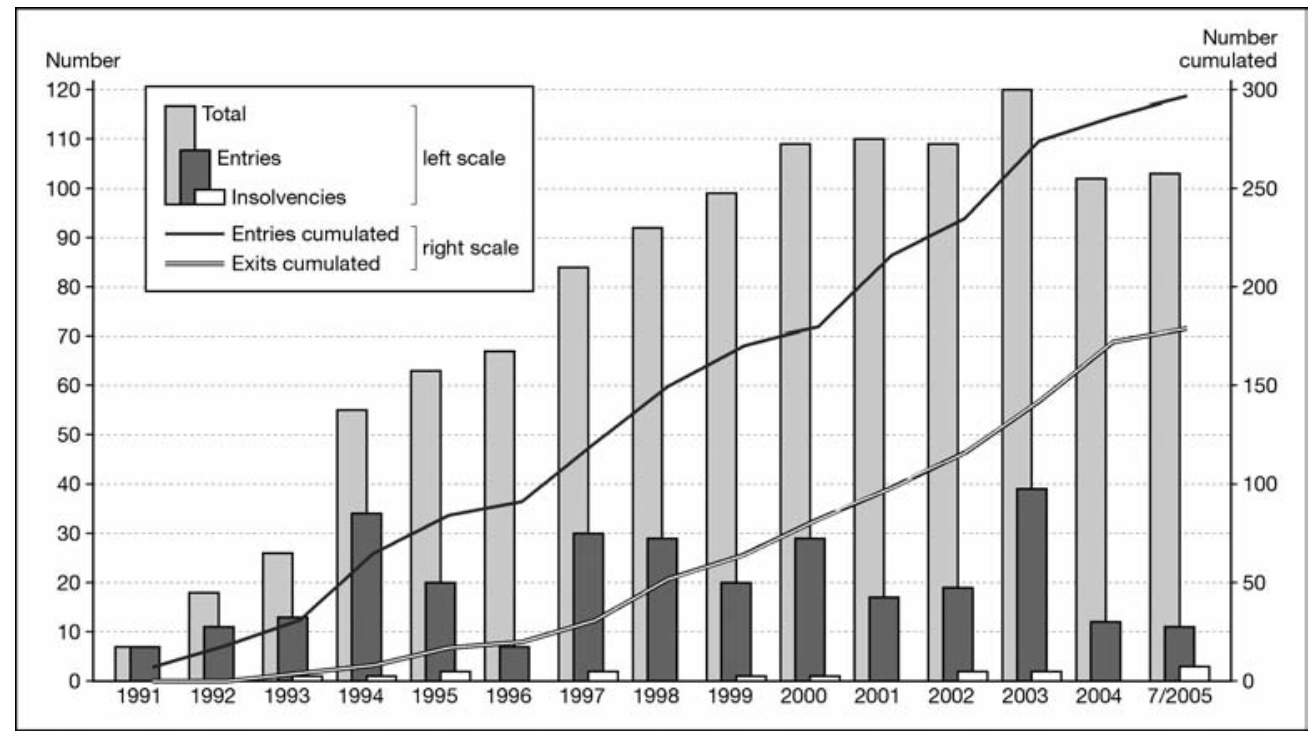

*Innovation and Business Incubation Center Berlin/East-West-Center Source: RAETZ 2005 
move to other locations. Up to now, 179 businesses have left the center in this manner. The technology center approach has no direct orientation towards special areas of activities in the sense of a cluster formation. There is an evaluation process for all units that want to establish activities in the center, but it is mainly based on whether the start-ups possess realistic future perspectives (usually documented by a convincing business plan) and not on their fields of activities corresponding to the profile of the technology park. This approach is typical for innovation centers (cf. BEHRENDT 1996; TAMASY 1996) but also illuminates the general policy approach of Berlin, which tends to follow the idea of spatial proximity rather than interlinked production activities.

In contrast to the IGZ/OWZ, the four other business centers offer permanently rentable spaces and are clearly oriented toward businesses with a focus on a particular subject area. Their establishment may be understood as a policy-led idea to generated competence in fields of technologies that seem to have good prospects in the future. These subject areas are chosen based on the main subject areas of the scientific and technological profile of Adlershof, and correspond with the present research facilities, above all in the areas of physics, chemistry, and information technology. This is the case for the center for photonic and optical technologies, the environmental technology center, the center for information technology, and the center for materials research. The subject area focuses of the businesses display a clear orientation toward identified fields of technological research in Adlershof, that is, toward information technology, materials research, photonics, and environmental technology (Tab. 2).

Altogether 400 private businesses with 4,279 employees and a revenue of 440 Mio. $€$ were settled in all six centers and other locations in technology park in the year 2006 (data according to WISTA 2007, also in the following, cf. Fig. 3). Another 201 businesses with 4,261 employees are located in the industrial park. Looking back on the development since the beginning, the private economy seems to have been quite successful. There has been a continuous increase in the number of enterprises and in the number of employees in the technology park (Fig. 4). And even though the average size of the enterprises (2006: 16.5 employees per unit) still is relatively small, they seem to be successful in the market. Indicators for this, aside from the low insolvency rate, include a constant reduction in the share of state subsidies to these enterprises (Tab. 3) and a strong increase in turnover. In 1997 the share of state subsidies was $26.4 \%$ of the turnover, but it had been reduced to $3.4 \%$ by 2007 . In the same period the turnover increased by

Tab. 2: Technology areas of technology park enterprises

\begin{tabular}{|c|c|c|c|c|c|c|}
\hline & \multicolumn{2}{|c|}{ Businesses } & \multicolumn{2}{|c|}{ Employees } & \multicolumn{2}{|c|}{ Turnover } \\
\hline & abs. & $\%$ & abs. & $\%$ & (Mio. $€)$ & $\%$ \\
\hline $\begin{array}{l}\text { Information and media } \\
\text { technology }\end{array}$ & 78 & 19.5 & 791 & 18.5 & 84,356 & 20.1 \\
\hline $\begin{array}{l}\text { Materials and microsystems } \\
\text { technology }\end{array}$ & 39 & 9.8 & 578 & 13.5 & 44,564 & 10.6 \\
\hline $\begin{array}{l}\text { Photonic and optic } \\
\text { technology }\end{array}$ & 54 & 13.5 & 867 & 20.3 & 97,503 & 23.3 \\
\hline $\begin{array}{l}\text { Environmental, biological, } \\
\text { and energy technology }\end{array}$ & 65 & 16.3 & 734 & 16.9 & 43,848 & 10.4 \\
\hline Others and service industry & 164 & 41.0 & 1319 & 30.8 & 149,843 & 35.7 \\
\hline Total & 400 & 100.0 & 4279 & 100.0 & 420,114 & 100.0 \\
\hline
\end{tabular}


$86.4 \%$ from 257 Mio. $€$ to 479 Mio. $€$. From these indicators one can get the impression that the enterprises have developed an independent economic base. However, up to now, no very large firm has settled in Adlershof or developed there. This is on the one hand not very unusual, as the relocation potential of large firms is generally low and small businesses do not develop so quickly. On the other hand, cluster approaches such as that of geographical industrialization stress the meaning of "flagship enterprises" for growth dynamic and competitive ability of a site, so that these circumstances can be viewed as a still-existing weakness in development.

\section{Research and university institutes}

The development of research and university institutes was strongly influenced by the idea to establish units doing research in areas most pertinent to the technology park. The spatial proximity of these units was hoped to generate the exchange of ideas between research and production and the transfer of personnel (including students). But once again the basic approach was spatial proximity; additional subsidies for cooperation were not given. Being publicly financed (usually half by the state of Berlin and half by the federal government of Germany), the influence of spatial policy on the locational decision was much stronger than on enterprises of the private sector. Based on concepts evaluated by the German Research Council (Wissenschaftsrat), units were established which partly contributed to the technology fields. Especially the orientation towards materials research, photonics, and information technology is strong; it finds its expression both in research institutes/university institutes and private enterprises (Tab. 2). Contributions to material research and photonics come for the university institutes of physics and chemistry, from the electron accelerator BESSY II (Berlin Electron Synchrotron Particle Accelerator), the Institut für Kristallzüchtung, IKZ (Institute for Crystal Growth), and the Institut für Angewandte Chemie, Adlershof, ACA (Adlershof Institute for Applied Chemistry). Developments in the area of information technology are done in the university institutes of mathematics and information sciences and the Fraunhofer Institut für Rechnerarchitektur und Softwaretechnik, FIRST (Fraunhofer Institute for Computer Architecture and Software Technology). Today twelve research facilities are located in Adlershof, employing approximately 1.500 persons in 2006 (Tab. 1). Their basic financing is derived from state and federal budgets in the amount of 101 Mio. $€$; the facilities themselves raise additional third-party funds (from research foundations and contracts) in the amount of 41 Mio. $€$.

Although the first decisions about relocating Humboldt University's natural sciences institutes were made in 1991, and the concrete planning, including bidding for the construction work, began in 1993, the move was contested for quite some time, actually until its

Fig. 4: Berlin-Adlershof: number of enterprises and employees 1996-2006

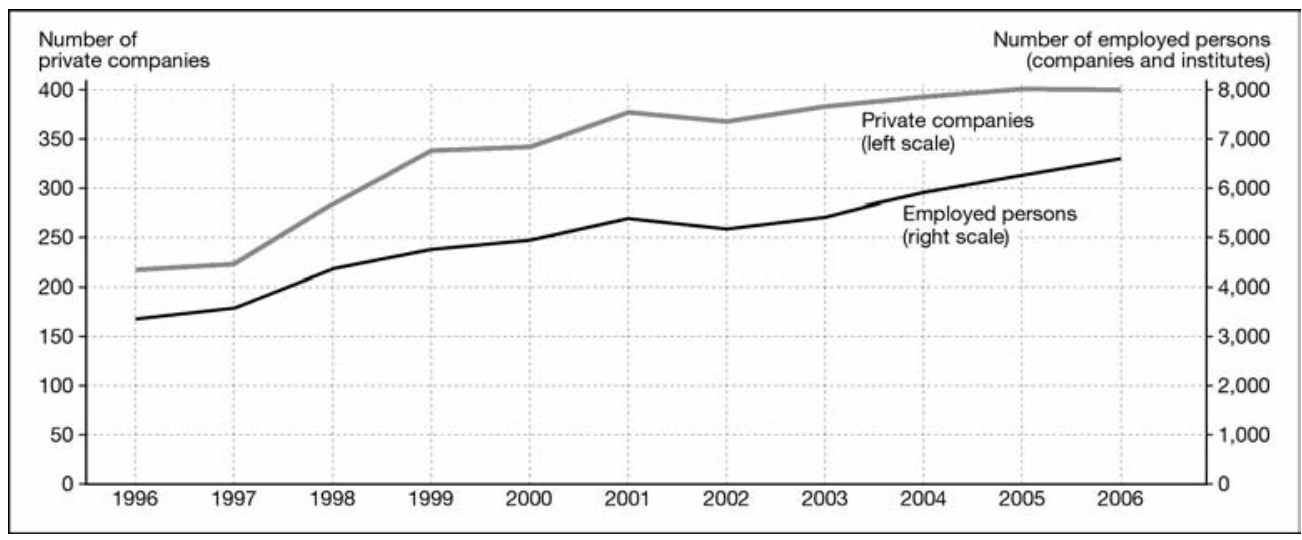

Source: WISTA 2007 
completion. Those belonging to the university were aware of the absolute necessity of acquiring adequate facilities for the natural sciences institutes. In Berlin's Mitte district, these were in buildings located in substantial distances from one another, which were in partly dilapidated condition, possessed no suitable equipment for modern research, and, because of their spatial separation, impeding intra- and interdisciplinary projects. All the same, a great deal of resistance arose in the scientists affected by the decision to relocate to the new site in Adlershof, which was almost fifteen kilometers away, southeast of Berlin, in what was subjectively viewed as a desert environment. It was publicly argued that, under these conditions, networks with vital research (e.g. joint projects) and training (e.g. with educational courses of study) in the economic and social sciences institutions and with medicine could not be maintained. Oftentimes however, personal reasons, such as the considerably longer commuting time or the loss of a site in the historically important area along Berlin's famous lane Unter den Linden, played some role. The relocation was ultimately decided in 1997 with a vote from the scientific counsel and the approval of the financial plan by the building commission.

The Institute of Information Science had to relocate as early as 1998, more or less compulsorily (the lease at the old site ran out; the Berlin senate refused renewal), not to a new building, but to an empty office building in Adlershof. Because of this, the basic setup of the relocation plan, which had actually been written with the intended timeframe of 2001 to 2007 , completely changed. As relocation stretched out over the long timeframe from 1998 to 2007 , it threatened to hamper the working ability of those involved considerably. But, with the formulation of a new concept - the so-called acceleration plan - the planned timeframe of 1998 to 2003 was successfully shortened via the regrouping of investments (e.g. barrack renovation rather than new construction, unification of information science and mathematics, reallocation of the annual governmental investment funds). Despite considerable resistance (due to having to relinquish demands for a suitable new building) the Institute of Mathematics followed in 2000 to the same building, which had actually been intended for service industries. New buildings for the institutes of chemistry (move in 2001) and physics (move in 2003) were erected, while two former barracks were arranged for psychology and geography (move in 2003). The opening of the Erwin Schrödinger Center in 2003 was of central importance for the site as a whole and also for the realization of an innovative milieu. It contained a central library, computer infrastructure, and course rooms - and, with its cafeteria and bookstore, it also offered the possibility for actors to meet. Today in Adlershof there are six university institutes with around 100 professorships and over 800 employees; approximately 6,400 students are presently receiving training there (Fig. 2, Tab. 1).

The description of the Humboldt University resettlement process displays the individual restraints against the relocation. And even after being relocated to the technology park Adlershof, cooperation with the private sector is often less recognized then basic research; for example the distribution of the university funds is based on third-party grants in basic research and does not consider cooperations with private enterprises. In general there are no subsidies given for network formation in Adlershof, even though spatial economic policy is expecting these to develop. This could be addressed as a weakness in recent spatial economic policy. Policy is more and more led by the idea of cluster formation and network development (cf. FromHOLD-EISEBITH/EISEBITH 2005; STERNBERG/SCHÄTZL 2004), but the use of formal or informal systems of network management is still limited.

Tab. 3: State subsidies for private enterprises (\% of turnover) 


\section{Economic performance and network development in Adlershof}

There is no general checklist available for the evaluation of clusters, but it is widely accepted that not every spatial concentration of activities is really a network-based cluster. For the existence of cluster formations, there have to be intensive linkages between the units, which have to receive innovative and competitive advantages from them. KRÄTKE/ SCHEUPLEIN $(2001,57)$ point out the mismatch between theoretical approaches to and empirical analysis of cluster formation. They argue based on considerations of REHFELD (1999) that locations with concentrations of successful units are often explained by the existence of linkages (without really analyzing them) and afterwards it is concluded that the success comes from the spatial proximity. But for the identification of cluster-like structures, an analysis of linkages has to be done based on a survey of the networks of enterprises (KRÄTKE/SCHEUPLEIN 2001, 61 f.). The dimensions of cluster formation have been discussed intensively by MALMBERG/MASKELL (2001) and have been completed by BATHELT/ GLÜCKLER $(2002,212 \mathrm{f}$.). They assert that a cluster is characterrized by four dimensions; horizontal, vertical, institutional, external. The horizontal dimension describes co-presence at a location, which facilitates the observation of competitors, the comparison of products and processes, and thereby the improvement of individual solutions. The vertical dimension is based on the input-output linkages of complementary units. The institutional dimension explains that formal and informal institutions, regulatory systems, trust, and reliability promote competitive strength. The external dimension argues that a cluster has to have additional external links to overcome the risk of overembeddedness or lock-in.

In the following analysis three elements are discussed that are linked with the idea of cluster dimensions but are considering the special situation of policy-led developments (cf. FROMHOLD-EISEBITH/EISEBITH 2005; STERNBERG/SCHÄTZL 2004). For the evaluation of the location Adlershof, and to answer the question whether it already possesses some cluster-like structures, there seem to be at least three relevant aspects:

- First, from a mere locational viewpoint it should be documented as to whether com- plementary units from the private sector, from research, and from public/private institutions are located within the area. This aspect analyzes the horizontal elements of a competitive cluster-like concentration of activities and it gives an impression of the cooperation potential and the possibilities of observing new competitor developments.

- Second, with a more statistical viewpoint, the economic performance and quantitative success should be analyzed. This element tries to illuminate the overall economic strength of the location, which in the sense of KRÄTKE/SCHEUPLEIN (2001) is often used as an argument for the existence of a cluster.

- Third, there should be a qualitative impression as to what extent the single units are really linked with each other within a network, and whether these immaterial connections (e.g. information transfer) are contributing to the innovative and competitive strength of the location. This element considers the vertical and institutional aspects of cluster formations.

The analysis is based on different information sources that were collected in various ways. Secondary statistics are available in WISTA's annual data publication; the annual report documents data from all the enterprises and institutions in the technology park and thereby provides information about totals. The data collection is annually done in the same way by an independent research institute hired by WISTA, and can therefore be used as quite a reliable base for the analysis of long-term developments. Primary statistics are based on several smaller case studies that were done in the Department of Geography at Humboldt University; they focus especially on linkages between different groups of actors in the location, and thereby enlighten aspects of the network formation in Adlershof.

\section{Complementary units}

The discussion above has shown that up to now all of the important components of an innovative cluster - research, education, institutions, enterprises - have been established in Adlershof. It is not only that the three cornerstones of the private sector, the university research and education, and the research institutes are located there. In addition, important institutions for the management of the park 
(such as WISTA and Initiativgemeinschaft Außeruniversitärer Forschungseinrichtungen in Adlershof e.V., IGAFA) and for the start-up firms (like IGZ and OWZ) have been established. The Schrödinger Center opens possibilities for information and communication, and there are retail facilities and restaurants for additional activities.

It also appears that a limited number of technological fields have successfully developed (Tab. 2) in which, due to the number of businesses and scientific institutes involved, a critical mass for the development of a cluster has been reached. This includes above all the areas of photonics and optical technologies, information and media technology, and materials research and technology. The currently active businesses in these fields find complementary facilities on site (physics, information technology, chemistry) with which scientific and personnel transfer is possible. The area of environmental, biological, and energy technology, in which less scientific activities on site can be found, is proliferating somewhat less and also with below-average growth rates (WISTA 2006); this is probably derived from the fact that the Institute of Biology was actually the only Humboldt University natural sciences institute not to be relocated to Adlershof. These developments point to a connection between science and economy.

\section{Performance and success}

The Adlershof growth dynamic speaks for the decisive competitive ability of its private business activities. The number of businesses and their employees, as well as the amount of revenue earned over the last decade, are a testament to a sustained growth process, not only in the centers for new businesses but also in the remaining area of the park. The low rate of insolvency (Fig. 3) and the decreasing share of subsidies (Tab. 3) also prove a successful development. In the publicly aided scientific facilities, the development dynamic cannot be analyzed in such a manner, as their financial basis is strongly dependent on the current state of the public budget.

That the development dynamic of businesses in Adlershof does not alone depend on internal business factors was shown in a 2003 poll of businesses contracted by WISTA (WISTA 2004). On a qualitative scale (1 to 3 ), businesses very positively rated the image of the location (1.29), the choice of commercial space (1.30), the availability of a qualified work force (1.45), and the possibilities for cooperation (1.45). Especially the possibility of personnel transfer between university and economy is a clear advantage of the location and of formations of this type. And the positive evaluation of cooperation potential gives the impression that the existing spatial proximity is already used as a basis for network formation. In contrast to this, elements in the surrounding environment such as the availability of parking (2.04) and free-time or sport activities (2.29) were rated less favorably. The results are in accordance with the assumptions of the models, namely that factors such as image, personnel transfer, and cooperation constitute a substantial element in the development of an innovative milieu.

\section{Networks}

The results discussed up to this point suggest the plausibility of the creation of an innovative milieu, but do not yet document the actual development of networks. Reliable data to this purpose is exceedingly difficult to come by, as networks are based for the most part on personal and informal contacts between actors. Formalized contacts can be documented between Humboldt University institutes and the applied research facilities taking the form of shared appointed employees (so-called s-professorships), cooperation agreements, and common projects funded by third parties (Fig. 5 ; based on information from the HU). The absolute number and intensity of these shared projects has clearly increased in the last years. So it was that eight shared appointments (out of fifteen s-professorships in total) of the university institutes came from scientific facilities in Adlershof and were newly established during the last decade. In six of twelve applied research facilities, contractually secured work cooperation has arisen. Alongside this, there are common research projects in special research areas, research groups, and post-graduate programs. A graduate school (for doctoral candidates) is currently being established as a cooperation between the university institutes and applied research facilities. It can therefore be asserted that strong networks between scientific facilities exist at this point.

Indications of the degree of network building between the university and businesses were given in a 2004 field study in economic geog- 
raphy (the following data is given according to the results of the study; cf. WEBER-BLEYLE 2008), which comprised a sample of 86 businesses (total during this time 217; return rate $39.6 \%$ ). Of the businesses asked, $19.2 \%$ were spin-offs of the university and around half possessed contacts with the university in various forms (e.g. personnel, projects). The share of personnel formerly trained at Berlin universities is still comparatively low (only $17.1 \%$ ); this may however be a result of the founding of the businesses before the time of the university relocation.

However, the businesses in Adlershof value their university contacts less than their relationships with other business on location and with the Technical University of Berlin (TU). This is evidence of the known phenomenon that oftentimes developmental, that is technical solutions such as those offered by the TU, are more important for the success of a busi-

Fig. 5: Formalized contacts* between Humboldt University institutes and applied research institutes in Berin-Adlershof (2008)

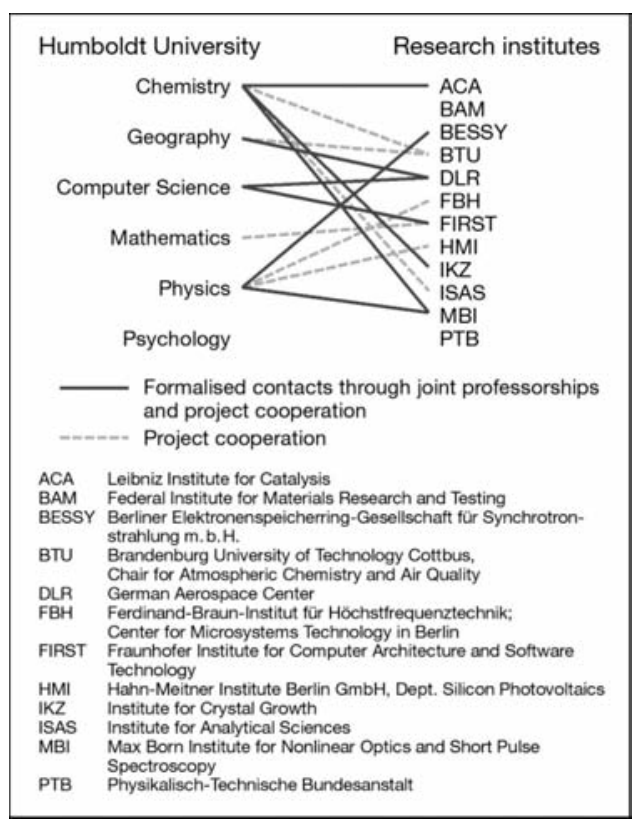

*shared professorships, cooperation agreements, ongoing shared projects

Source: Information of Humboldt University ness than basic research in natural sciences. The research also proves a discussed presumption of the model approaches, that contacts between businesses are of special importance for business success; on a 5-step scale of importance $(1=$ excellent, $5=$ bad $)$, those asked valued these contacts on average at 1.9, or of more than average importance.

To identify the importance of networks for the economic success of the enterprises, a statistical cluster analysis was done (WEBER-BLEYLE $2008,71 \mathrm{f}$ ). It evaluated the connection between business success of the interviewed enterprises (measured by the growth of the number of employees) and the type and intensity of networks of these units. The results show the highest growth rates for businesses with intensive contacts to other businesses in Adlershof, and with moderately pronounced relationships to the university. Businesses that focused heavily on the university rather than on other businesses were somewhat less successful in personnel growth. The least growth rates were displayed by businesses with no interactions with the university or other businesses. The results confirm the general presumption of the importance of networks; but it seems that linkages with other firms (to find technical solutions) are more important for economic success than with university research (doing more basic research).

Overall the results as far as network creation show that Adlershof forms an intensively interconnected scientific cluster. The university institutes have continued with their contacts to Berlin-Mitte and have developed in addition new networks with research institutes in Berlin-Adlershof. These contacts have been developing relatively fast and have reached a high degree of intensity. Networks between university and enterprises are developing more slowly. But an economic cluster - with contacts between the enterprises - has also developed with positive effect on the economic success of the businesses connected to it. The contacts that have arisen between science and business are up to this point less distinct but existent; one should be careful to note in this analysis that the university institutes only settled relatively recently in Adlershof.

The discussion of the pathway of development and characteristics of the science and business network in Adlershof gives the im- 
pression that the site fulfils several elements of an innovative cluster. Not only complementary units are existing, but in addition the locations shows a highly developmental dynamic. And the network analysis documents that those units that are more linked to other units at the location display better economic performance.

\section{Conclusion}

The question as to whether regional economic policy may successfully develop an innovative milieu by means of initial investments cannot be conclusively answered at present (see the discussion of COOKE 2002, $156 \mathrm{f}$.). The overwhelming majority of indicators for Adlershof point to the success of the project. The economic dynamic of the businesses is apparent according to revenue and employee growth rates, as well as low insolvency rates and decreased shares of subsidies, now reduced to a very low level. And businesses that are networked with other businesses operate especially successfully. These indicators give the impression that the proximity-oriented approach of spatial economic policy has been successful. Similarly, networks between the scientific facilities are developing. The site has also been noticed by the public, as the numerous existing articles about Adlershof show, and the assessment of the site's image and the entities settled there is clearly quite positive. But the networks between science and business are as yet not very strongly pronounced, so that the impression almost arises that a single site has been settled by both a science park and a business park. The large flagships of economic development are also still missing. However, when assessing these stillexisting limitations, the as yet comparably young development phase of the site should be considered. In all, the Adlershof project can be classified as a clear success in regional economic policy. However, with respect to the scientific question of the possibility of generating an innovative milieu with a long-term growth dynamic and a high rate of networks, a conclusive answer is not yet possible.

\section{Note}

Mrs. Rose Knudsen deserves thanks for linguistic editing.

\section{References}

ARL (Akademie für Raumforschung und Landesplanung)(2006): Wie hell strahlen Leuchttürme? Anmerkungen zur Clusterpolitik im ländlichen Raum. In: ARL, 3, 1-4.

Asheim, B./Cooke, P./Martin, R. (Ed.) (2006): Clusters and regional development. Milton Park/New York.

Aydalot, P. (Ed.) (1986). Millieux innovateurs en Europe. Paris.

BATHELT, H. (1992). Erklärungsansätze industrieller Standortentscheidungen. In: Geographische Zeitschrift, 80, 195-213.

BAthelt, H. (1998). Regionales Wachstum in vernetzten Strukturen: Konzeptioneller Überblick und kritische Bewertung des Phänomens „Drittes Italien“. Die Erde, (129)3, 247-271.

BATHELT, H./DEPNER, H. (2003): Innovation, Institution und Region: Zur Diskussion über nationale und regionale Innovationssysteme. In: Erdkunde 57, 126-143.

BAthelt, H./GlÜCKLER, J. (2002): Wirtschaftsgeographie. Stuttgart.

BEHRENDT, H. (1996): Wirkungsanalyse von Technologie- und Gründerzentren in Westdeutschland. Heidelberg.

Belussi, F. (2006): In search of a theory of spatial clustering. In: Asheim, B./Cooke, P./Martin, R. (Ed.)(2006): Clusters and regional development. Milton Park/New York, 69-89.

Boschma, R.A./Frenken, K. (2005): Why is economic geography not an evolutionary science? Towards an evolutionary economic geography. Utrecht. (Papers in Evolutionary economic geography.

CoOKe, P. (2002): Knowledge economies - clusters learning and cooperative advantages. London/New York.

Cooke, P./Piccaluga, A. (2006): Regional development in the knowledge economy. Milton Park/New York.

DANNENBERG, P. (2007): Cluster-Strukturen in landwirtschaftlichen Wertschöpfungsketten in Ostdeutschland und Polen. Münster/Hamburg/London. (Wirtschaftsgeographie, Band 43).

FESER, E. (1998): Old and new theories of industry clusters. In: Steiner, M. (Ed.): Clusters and regional specialisation - on geography, technology and networks. London, 18-40.

Floeting, H. (2008): Clusterinitiativen und Netzwerke - Handlungsfelder der Wirtschaftsförderung. In: DifuBerichte, 2, 8-9.

Fromhold-Eisebith, M. (1999): Das „kreative Milieu“ - nur theoretisches Konzept oder Instrument der Regionalentwicklung? In: Raumforschung und Raumordnung, 2/3, 168-175.

Fromhold-EISEBITH, M. (2000). Technologieregionen in Asiens Newly Industrialized Countries. Münster/ Hamburg/London. (Wirtschaftsgeographie, Band 18).

Fromhold-Eisebith, M./Eisebith, G. (2005): How to institutionalize innovative clusters? Comparing explecit 
top-down and bottom-up approaches. In: Research policy, 34, 1250-1268.

GERTLER, M. (2001): Best practice? Geography, learning and the institutional limits of strong convergence. In: Journal of Economic Geography, 1, S. 5-26.

GORDON, I.R./MCCANN, P. (2000): Industrial clusters: complexes, agglomeration and/or social networks? In: Urban Studies 37, 513-532.

Grotz, R. (1996). Kreative Milieus und Netzwerke als Triebkräfte der Wirtschaft: Ansprüche, Hoffnungen und Wirklichkeit. Bayreuth, 65-84. (Arbeitsmaterialien zur Raumordnung und Raumplanung, Heft 153).

Gundel, S./Lutmann, J. (2008): Die regionalwirtschaftlichen Effekte von TechnologieZentrum und TechnologiePark Dortmund. Münster.

HU (Humboldt-Universität zu Berlin (Ed.)(2005). Adlershof Campus. Berlin.

Johnston, R.J./Taylor, P.J./Watts, M.J. (Eds.)(1995). Geographies of global change. Oxford.

Kline, S.J./RosenberG, N. (1986): An overview of innovation. In: Landau, R./Rosenberg, N. (Ed.): The positive sum strategy - harnessing technology for economic growth. Washington, 275-307.

KrÄtKe, S./SCHEUPLEIN, C. (2001): Produktionscluster in Ostdeutschland. Hamburg.

Kulke, E. (2003): Berlin - German Capital and Global City? In: Die Erde, (134)3, 219-233.

Kulke, E. (2008). Wirtschaftsgeographie. Paderborn/München/Wien/Zürich.

MalmberG, A./Maskell, P. (2001): The elusive concept of localization economies. Towards a knowledgebased theory of spatial clustering. New York. (Paper for the AAG Annual Conference).

Mossig, I. (2006): Netzwerke der Kulturökonomie. Bielefeld.

Mossig, I./KLeIN, J. (2003): Das Produktionscluster der optischen Industrie im Raum Wetzlar. In: Raumforschung und Raumordnung 61, p. 237-251.

Porter, M. E. (1993): Nationale Wettbewerbsvorteile. Wien.
Porter, M. E. (1998): Clusters and the new economics of competition. In: Harvard Business Review, (76)6, 77-90.

PorTer, M. E. (1999): Unternehmen können von regionalen Vernetzungen profitieren. In: Harvard Business Manager 3, 51-63.

RAETZ, G. (2005). Materialien zum Innovations- und Gründerzentrum Berlin-Adlershof.

RAEtZ, G. /SEIFF, F. (2003): 20 Jahre Berliner Innovations- und Gründerzentrum - eine Bilanz. Berlin.

REHFELD, D. (1999): Produktionscluster. Konzeption, Analyse und Strategien für eine Neuorientierung der regionalen Strukturpolitik. München.

Schamp, E. W. (2007): Denkstile in der deutschen Wirtschaftsgeographie. In: Zeitschrift für Wirtschaftsgeographie, (51)3-4, 238-252.

SternBERG, R./SchÄtZl, L. (2004): Clusteransätze in der regionalen Wirtschaftsförderung. In: Zeitschrift für Wirtschaftsgeographie, (48)3-4, 164-181.

STORPER, M./WALKER, R. (1989). The capitalist imperative - territory, technology, and industrial growth. Oxford.

TAMASY, C. (1996). Technologie- und Gründerzentren in Ostdeutschland - eine regionalwirtschaftliche Analyse. Münster/Hamburg/London. (Wirtschaftsgeographie, Band 10).

Weber-Bleyle, M. (2008). Netzwerke und Wissenstransfer in Technologieparks: Eine Bewertung der Beziehungen zwischen universitären Forschungseinrichtungen und Unternehmen aus Unternehmersicht an den Beispielen Berlin-Adlershof und Urbana-Champaign. Berlin. (Magisterarbeit, HU-Berlin)

WISTA (2004) (Ed.). Ergebnisse der Jahresumfrage 2003. Berlin.

WISTA (2006a) (Ed.). Bericht über Adlershof. Berlin.

WISTA (2006b) (Ed.). Adlershof Magazin/ILA 2006. Berlin.

WISTA (2007, 2008) (Ed.): Bericht über Adlershof. Berlin. 